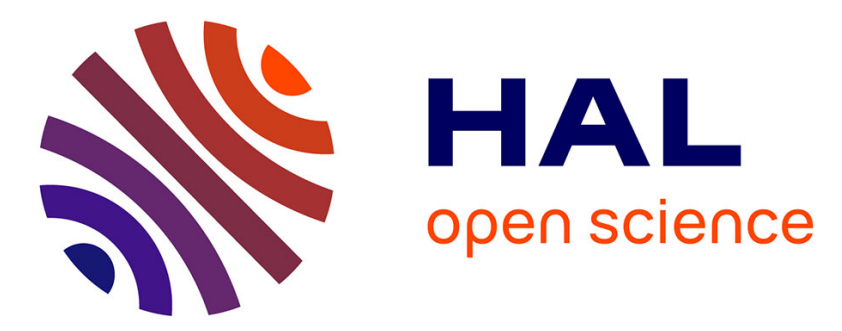

\title{
Some aspects of cellulose ethers influence on water transport and porous structure of cement-based materials
}

Jérémie Pourchez, Bertrand Ruot, Johan Debayle, Emilie Rouèche-Pourchez, Philippe Grosseau

\section{To cite this version:}

Jérémie Pourchez, Bertrand Ruot, Johan Debayle, Emilie Rouèche-Pourchez, Philippe Grosseau. Some aspects of cellulose ethers influence on water transport and porous structure of cement-based materials. Cement and Concrete Research, 2010, 40 (2), pp.242-252. 10.1016/j.cemconres.2009.10.008 . hal00464184

\section{HAL Id: hal-00464184 \\ https://hal.science/hal-00464184}

Submitted on 16 Mar 2010

HAL is a multi-disciplinary open access archive for the deposit and dissemination of scientific research documents, whether they are published or not. The documents may come from teaching and research institutions in France or abroad, or from public or private research centers.
L'archive ouverte pluridisciplinaire $\mathbf{H A L}$, est destinée au dépôt et à la diffusion de documents scientifiques de niveau recherche, publiés ou non, émanant des établissements d'enseignement et de recherche français ou étrangers, des laboratoires publics ou privés. 


\title{
Some aspects of cellulose ethers influence on water transport and porous structure of cement-based materials
}

\author{
POURCHEZ J érémie (1) * RUOT Bertrand(2), DEBAYLE J ohan(3) , POURCHEZ Emilie(4), \\ GROSSEAU Philippe(1)
}

(1) Ecole Nationale Supérieure des Mines de Saint Etienne, Centre SPIN Département PMMC ; LPMG -UMR CNRS 5148, 158 Cours Fauriel - 42023 Saint-Étienne Cedex 2, France

(2) Scientific and Technical Centre for Building (CSTB); 24, rue J oseph Fourier 38400 Saint-Martin d'Hères - France

(3) Ecole Nationale Supérieure des Mines de Saint Etienne, Centre CIS Département DIM ; LPMG -UMR CNRS 5148, 158 Cours Fauriel - 42023 Saint-Étienne Cedex 2, France

(4) Ecole Nationale Supérieure des Mines de Saint Etienne, Centre SPIN Département ProcESS ; LPMG -UMR CNRS 5148, 158 Cours Fauriel - 42023 Saint-Étienne Cedex 2, France

\begin{abstract}
:
This paper evaluates and compares the impact of cellulose ethers (CE) on water transport and porous structure of cement-based materials in both fresh and hardened state. Investigations of the porous network (mercury intrusion porosimetry, apparent density, 2D and 3D observations) emphasize an air-entrained stabilisation depending on CE chemistry. We also highlight that CE chemistry leads to a gradual effect on characteristics of the water transport. The global tendencies brought by $\mathrm{CE}$ are: higher water retention, lower capillarity water absorption, lower liquid water permeability as well as higher water vapour permeability. All things considered, we demonstrate that $\mathrm{CE}$ chemistry is an important controlling factor on water transport and porous structure evolution.
\end{abstract}

Keywords:

Cellulose ethers; Porous structure; Water transport; Microtomography

\section{Introduction}

\section{I.1. Context and objectives}

Depending on the applications, factory-made mortars are mainly composed of mineral binders (cement, lime and/or gypsum), sands, aggregates and additives (e.g. fillers). They also contain different kinds of admixtures (i.e. organic components) in order to bring some particular properties to the fresh paste up to the hardened material. Such admixtures may interact on the other components of the formulation, in particular the binder.

Water control is a major issue in all kind of mortars because it plays on dry-out of the render, workability and crack resistance. As a result, the development of admixtures combining rheological and water retention properties represents significant economic stakes in the mortar industry. To reach this objective, cellulose ethers (CE) are admixtures usually introduced into mortar formulations. The effect of a CE molecule on macroscopic mortars' properties (mainly open time, water transport, paste consistency and entrained air) is generally known or quite easily measured experimentally. However, there is still a poor comprehension of the associated mechanisms. In particular, even if the influence of $\mathrm{CE}$

*Auteur à qui la correspondance devait être adressée : pourchez@emse.fr 
structural parameters (molecular mass, nature and content of substitution groups) on cement hydration kinetics is currently quite-established, their impact with regard to water transport and porous structure is not elucidated.

These organo-mineral interactions appear all the more complex to investigate as industrial mortars may contain up to several dozens of components. A lack of basic data remains on the influence of CE chemistry microstructure and water transport. Following the overall objective of a fundamental understanding of phenomena and mechanisms governing mortar behaviours, this paper proposed a first approach dedicated to the impact of CE chemistry on the porous structure and hydric transfer of cement-based materials.

\section{I.2. Background of CE impact on microstructure}

Few studies were devoted to the impact of $\mathrm{CE}$ on the cementitious porous media. Malatrait et al. studied the impact of only one CE molecule on the mortar microstructure [1]. SEM observation emphasized that the porous media induced by their $\mathrm{CE}$ molecule may be described as a network of $100 \mu \mathrm{m}$-diameter air voids linked by "small canals" (i.e. large capillaries) with a size lower than $1 \mu \mathrm{m}$-diameter.

Silva et al. investigated the effects of EVA and HEC polymers on the pore structure of Portland cement paste by mercury intrusion porosimetry (MIP) [2]. Experiments were performed on one HEC molecule, with various curing methods and polymer to cement ratio. For HEC-containing pastes, the pore size distribution curves exhibit four peaks. The first peak lies approximately at the $4 \mathrm{~nm}$-diameter. The second one, which is the sharpest, corresponds to a diameter around $40-75 \mathrm{~nm}$. The third peak appears in the diameter of $100-500 \mathrm{~nm}$ and was in accordance with the large capillaries observed by Malatrait et al. between air voids. Finally, a fourth and less sharp peak was observed by Silva et al. on some admixed pastes due to entrained air (pore width larger than $100 \mu \mathrm{m}$ that may correspond to the air void network characterised by Malatrait et al.).

Jenni et al. investigated the role of one HEMC molecule on mortar microstructure changes [3] and [4]. These authors showed by pycnometry measurements that the air void content of CEcontaining mortars is about 20 vol.\%, whereas non-admixed mortars contain only a few volume percent. Jenni et al. proposed that air voids were entrained during mechanical mixing and stabilised by CE. This assumption seems to be confirmed by the polymer enrichment observed at the interface between air void and wet cement paste. The authors assigned this behaviour to the surface-active agent properties of $\mathrm{CE}$, which would have a strong affinity to the air-water interface. Results generated by Knapen et al. confirmed that hardening of cement mortars modified with CE implies polymer film formation [5].

Literature showed reliable and interesting results, however each study examines only one CE molecule. Even if a consensus is reached on the specific porous structure generated by $\mathrm{CE}$ (100 $\mu \mathrm{m}$-diameter air voids linked by large capillaries inferior to $1 \mu \mathrm{m}$ ), the effect of its chemistry on the cement-based material microstructure still remains poorly studied and understood.

\section{I.3. Background of CE impact on water transport}

Mortars are usually submitted to hydric constraints. In fresh state, mixing water can evaporate and be absorbed by the support material. This water lost is more or less fast according to climatic conditions and the nature of the support, respectively. In hardened state, renders may offer both rain penetration resistance and good water vapour permeability to decrease building humidity. In this context, the choice of $\mathrm{CE}$ molecule introduced in formulations appears as a key element in order to control the water balance as a function of hydric stresses. Analyses of the admixtures used in render formulations often showed some deficiencies on the finished products in specific applications [6]. Despite the improvement brought by $\mathrm{CE}$ on final properties of dry-mix render, very few studies deal with the understanding of $\mathrm{CE}$ chemistry influence on water transport properties in fresh and hardened state.

Paiva et al. examined the impact of one HPMC molecule on hardened state characteristics of mortar [7]. In term of drying process, these authors demonstrated that MHPC is able to retain 
water within mortars even in adverse conditions such as an external temperature of $40{ }^{\circ} \mathrm{C}$ and tests subject to ventilation. Moreover, Paiva et al. observed that MHPC also affects porosity through air entrainment yielding a reduction of strength. The water retention capacities of different fresh polymer-modified mortar were yet determined [8]. However this work was devoted to the influence of latexes and polyacrylic ester emulsions. Sometimes, the addition of hydrophobic admixtures on concrete water transport was also investigated [9]. Finally, some studies were also dedicated to the influence of mortar mineral additives (such as lime) [10] and [11]. Therefore, very few specific data were available in the literature concerning $\mathrm{CE}$ influence on hydric transfers.

\section{Materials}

\section{II.1. Cellulose ethers}

$\mathrm{CE}$ are water-soluble semi-synthetic polymers derived from cellulose. Among the wide variety of existing $\mathrm{CE}$, three types are mainly used in mortar manufacturing: hydroxypropylmethyl cellulose (HPMC), hydroxyethylmethyl cellulose (HEMC) and hydroxyethyl cellulose (HEC). Such polymers are completely determined by two parameters:

* The molecular weight (weight-average molecular mass $\mathrm{M}_{\mathrm{w}}$ ),

* The nature and the content of the substitution groups, methoxyl - $\mathrm{OCH}_{3}$ (in $\mathrm{HPMC}$ and HEMC), hydroxypropyl - $\left(\mathrm{CH}_{2}\right)_{3} \mathrm{OH}$ or POOH (in HPMC) and hydroxyethyl $-\left(\mathrm{CH}_{2}\right)_{2} \mathrm{OH}$ or EOOH (in HEMC and HEC).

In Europe, the most widely used CE for building materials are both HEMC and HPMC, while HEC are sometimes used in South America. In this paper, five CE were studied: two HPMCs noted U2 and P1; three HECs noted H1, N1 and N7. Their molecular weights and the contents of substitution groups are previously determined [12]. These results are detailed in Table 1.

Table 1: Molecular parameters of the selected cellulose ethers.

\begin{tabular}{lllll}
\hline Admixtures & $\mathrm{M}_{\mathrm{w}}$ (Dalton) & $\mathrm{EOOH} \mathrm{( \% )}$ & $\mathrm{POOH}(\%)$ & $\mathrm{OCH}_{3}(\%)$ \\
\hline HPMC U2 & 955 OOO & & 10.65 & 27.5 \\
HPMC P1 & 175 OOO & & 19 & 27.5 \\
HEC H1 & 175 000 & 48.5 & & \\
HEC N1 & 175 O00 & 56 & & \\
HEC N7 & 1335 000 & 56 & & \\
\hline
\end{tabular}

II.2. Mineral compounds

The considered cement was a 52.5 ordinary Portland cement (CE $\mathrm{CP} 2$ according to the European standard NF EN 197-1). Its chemical and phase compositions are given in a previous paper [12]. X-ray fluorescence spectroscopy (Bruker-AXS, SRS3400) was conducted in order to determine the oxide composition and the phase composition according to Bogue approximation. XRD analysis (Siemens, D 5000) allowed also quantifying the phase composition of the given cement by means of Rietveld method (Siroquant V2.5 software). The influence of $\mathrm{CE}$ on macroscopic properties was studied with a cement paste or with a laboratory-made mortar composed of Portland CEM I $52.5 \mathrm{R}$ cement (30 wt.\%), siliceous sand (65 wt.\%), calcareous filler ( 5 wt.\%), and CE (0.27 wt.\% in addition to the above dry mix).

\section{Experimental methodologies}

III.1. Fixed parameters in admixed mortar formulations: kneading water and CE content or paste consistency?

In this paper, the following general notation is used: $\mathrm{C}$ refers to cement, $\mathrm{P}$ to polymeric admixture (i.e. cellulose ether) and $\mathrm{W}$ refers to water. The water to cement ratio (W/C) was always maintained at a constant value whatever the CE molecule introduced is (i.e. 1 in our laboratory-made mortar, and 0.4 in cement paste). This experimental methodology is well- 
adapted to basic research dealing with the impact of CE chemistry on mortar macroscopic properties, without any willingness neither on development of new products nor on evaluation of existing ones.

On the one hand, in industrial context the research of an optimal mortar formula consists in performing multivariate experimental designs for the optimization of the nature and amount of mineral/organic compounds. Thus, the CE-admixed mortar workability was as a general rule adjusted by changing both the kneading water content as well as the amount (or chemistry) of $\mathrm{CE}$ introduced. Finally, the content of each component introduced in formulations was accurately determined so as to achieve specified properties, and particularly to reach a given level of workability and water retention capacity. However, as many parameters was simultaneously modified, it remains quite difficult to establish if the macroscopic properties variation observed is mainly due to modifications of CE chemistry or changes in water content.

On the other hand, our basic objective is to improve our knowledge of CE impact on water transport and porous media. Therefore, it appears essential to fix a constant water to solid ratio in order to examine only the impact of CE chemistry (independently of a change of water content), even if the mortar workability obtained was not always complied with specifications followed in the case of factory-made mortar.

\section{III.2. Porous structure characterization of fresh and hardened cement pastes}

According to the considered objectives discussed above, this study is restrained to basic approaches. Thus, investigations of the microstructure were performed on the simplest model of cementitious material, i.e. the cement paste. The polymer to cement mass ratio $(\mathrm{P} / \mathrm{C})$ used is always equal to $0.5 \mathrm{wt} . \%$. The water to cement mass ratio $(\mathrm{W} / \mathrm{C})$ is fixed at 0.4 whatever the $\mathrm{CE}$ introduced is. Different methods were successively examined to establish the porous media organization: Mercury intrusion porosimetry (MIP), apparent density measurement, $2 \mathrm{D}$ observations by optical microscopy and $3 \mathrm{D}$ observations by synchrotron radiation X-ray microtomography.

MIP measurements were carried out with a low and a high pressure porosimeter (Micrometrics Autopore IV 9500). The volume of the test samples was always inferior to $5 \mathrm{~cm}^{3}$. The macropores' distribution was also studied from 2D optical microscopy observation of $256 \mathrm{~cm}^{2}$ of cement paste. The experimental conditions used lead to obtain a spatial resolution of $23.8 \mu \mathrm{m}$. 2D images were then filtered and thresholded to extract air voids. Finally, their number, surface and 2D distribution (with a diameter higher than $50 \mu \mathrm{m}$ ) were calculated. The specimens for MIP, apparent density measurements and 2D optical microscopy observation $(\mathrm{W} / \mathrm{C}=0.4-\mathrm{P} / \mathrm{C}=0.5 \%$ ) were 14 day-stored with controlled storage conditions (50 $\mathrm{RH} \%$ and $23^{\circ} \mathrm{C}$ ). Prior to experiments, the solid was vacuum-dried under $\mathrm{P}_{2} \mathrm{O}_{5}$ during $24 \mathrm{~h}$ to dry the samples.

$3 \mathrm{D}$ porous media of samples was performed using synchrotron radiation X-ray microtomography. These experiments were conducted at the European Synchrotron Radiation Facility (ESRF - ID19 beamline). The cement paste microstructure was investigated both in hardened state $\left(\mathrm{W} / \mathrm{C}=0.4-\mathrm{P} / \mathrm{C}=0.5 \%\right.$, cured during 14 days at $23^{\circ} \mathrm{C}$ and $50 \mathrm{RH} \%)$ and in fresh state $(\mathrm{W} / \mathrm{C}=0.5-\mathrm{P} / \mathrm{C}=0.5 \%$, observation during the first hour of hydration). In the hardened material, usual X-ray microtomography scans were performed on cylindrical cement paste specimen $(1.5 \mathrm{~mm}$-diameter and $1 \mathrm{~cm}$-long) with a spatial resolution of $0.7 \mu \mathrm{m}$ so as to emphasize very accurately the porous structure. However, usual $\mathrm{X}$-ray microtomography scans are too slow compared to the fast evolution of porosity in fresh cement-based material during the first hour of hydration. As a result, to follow such a phenomenon, fast X-ray microtomography is required.

In early ages, fast X-microtomography scans (with a scan time of $1.5 \mathrm{~min}$ ) were conducted on cylindrical cement paste specimen $(2.6 \mathrm{~mm}$-diameter and $1 \mathrm{~cm}$-long) with a spatial resolution of $2.8 \mu \mathrm{m}$. We must underline that we need a paste with higher $\mathrm{W} / \mathrm{C}$ in fresh state experiment (i.e. 0.5 compared to 0.4 in hardened state) in order to introduce with good reproducibility the fresh cement paste on such small cylindrical. Fast X-ray microtomography technique requires also short exposures times (obtained by relaxing the monochromaticity of the beam 
through the use of a multilayer monochromator or the so-called "pink" beam) as well as an efficient acquisition chain. A parallel architecture was implemented to read and store the recorded data and rotate the sample, while recording the following image. To get quantitative data, different steps of $3 \mathrm{D}$ image processing and analysis were performed. First, a morphological filtering was applied on images so as to reduce noise and artefacts. Second, smoothed images were thresholded to exhibit air voids. And last, distributions of air bubbles (number, surface or volume) were computed.

To examine CE affinity to the air-water interface, stained CE molecules were synthesized thanks to the experimental procedure initially developed by Jenni [3]. The staining technique, using fluorescein-5-isothiocynate (FITC), consists in dissolving CE and then FITC in dimethyl sulphoxide at $95^{\circ} \mathrm{C}$. The $\mathrm{CE}$ stained was then precipitated in tetra-hydro furane, isolated and re-dissolved in water to be used for cement-based material preparation.

\section{III.3. Water retention capacity of fresh mortar}

Any porous substrate exerts suction on freshly applied mortars leading most of the time to a loss of mixing water. Water retention is thus defined as the ability of a fresh mortar to retain water used for its preparation. The influence of five types of $\mathrm{CE}$ on water retention was studied using laboratory-made mortar. The mortar paste was prepared at $20{ }^{\circ} \mathrm{C}$ and $65 \mathrm{RH} \%$, with a water to cement ratio of 1 . As described in the last paragraph, a fixed water to dry-mix ratio was chosen (and thereby with a variable paste workability) in order to try to get the specific influence of CE chemistry.

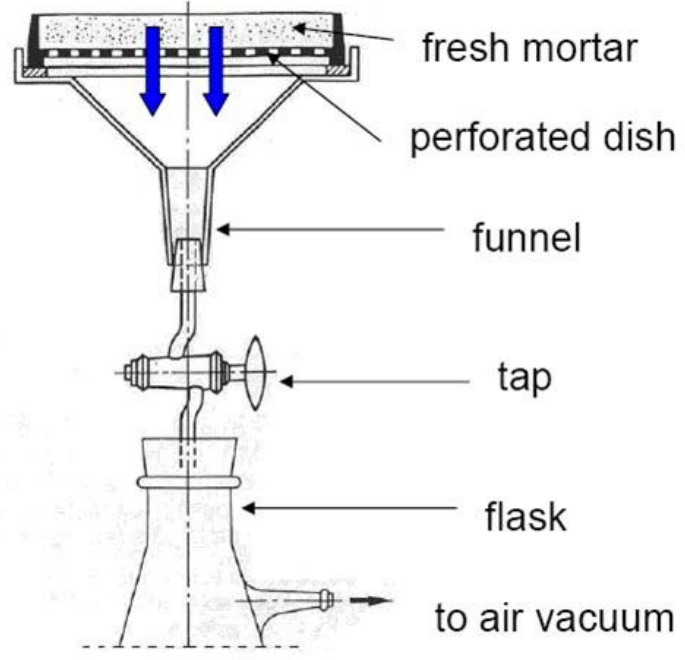

Figure 1: ASTM C91 test device to determine water retention of mortars.

Two normalized tests are often performed to quantify water retention of mortars. The first one, from an American standard (ASTM C91), is based on application of an air depression [13]. This methodology is also used in France for assessing one-coat renderings [14]. In this ASTM method, water retention is measured with the device shown in Figure 1, composed of a perforated dish attached to a vacuum assembly by a funnel. The dish is filled with the mortar and the vacuum is adjusted to maintain a depression of $50 \mathrm{~mm} \mathrm{Hg}$ during $15 \mathrm{~min}$. WR represents the water retention. It is calculated thanks to the initial weight of mixing water $\left(\mathrm{w}_{0}\right)$ and its weight loss after the depression period $\left(\mathrm{w}_{1}\right)$, as defined by the following (Equation 1):

WR $(\%)=100 \times \frac{W_{0}-W_{1}}{W_{0}}$

The principle of the second test, from a German standard (DIN 18555), consists in measuring water absorption by a filter paper at atmospheric pressure [15] . As shown in Figure 2, in the DIN method the mortar was poured into a conical ring previously placed on a filter paper 
covered with a non woven tissue. The assembly was weighed, and then it was covered with a plastic plate to avoid any water evaporation during the test. Finally it was left to stand for 5 min. By weight differences, the water retention WR (in \%) was easily deduced (Equation 2).

$\mathrm{WR}(\%)=100 \times \frac{\mathrm{m}_{1}-\mathrm{m}_{0}}{\mathrm{~m} \times \mathrm{W}}$

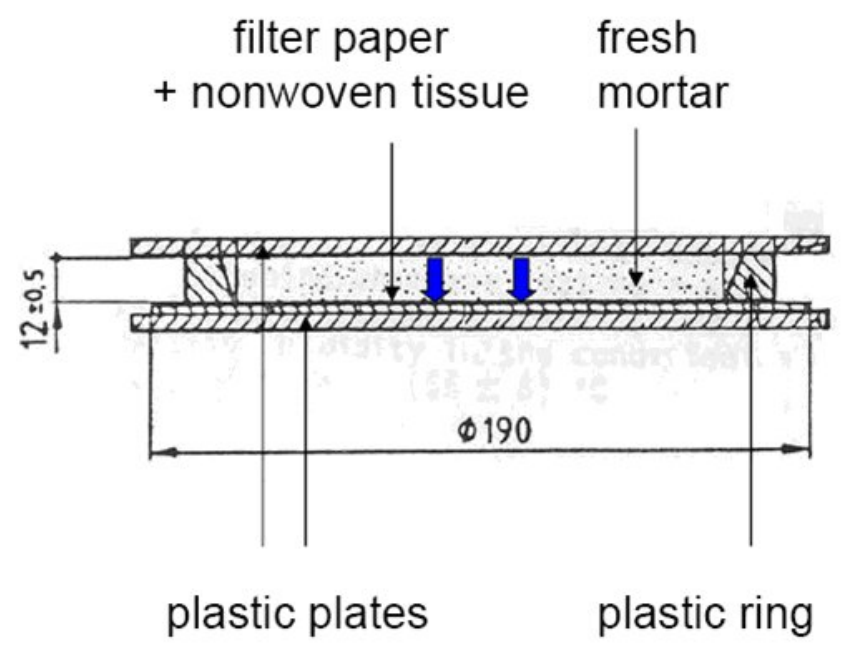

Figure 2: DIN 18555 test device to determine water retention of mortars. Dimensions are in mm.

Where $m_{1}$ was the mass of the soaked filter plate and the plastic plate after the test in $g, m_{0}$ was the initial mass of the dry filter plate and the plastic plate before the test in $\mathrm{g}, \mathrm{m}$ was the mass of mortar introduced in the plastic ring in $\mathrm{g}$, and $\mathrm{w}$ was the water content of the test mortar prepared.

III.4. Water vapour permeability and liquid water penetration

The main property of $\mathrm{CE}$ is to bring a high water retention capacity to the fresh paste. However, they may also have a significant impact on the hardened material hydric transfer such as liquid water penetration and water vapour permeability. Experiments were conducted on hardened cement pastes $(\mathrm{W} / \mathrm{C}=0.4$ and $\mathrm{P} / \mathrm{C}=0.5 \mathrm{wt} . \%)$. Materials were prepared as $10 \mathrm{~cm}$ diameter specimens with a thickness of $1 \mathrm{~cm}$, cured for about 28 days at $23{ }^{\circ} \mathrm{C}$ and 50 $\mathrm{RH} \%$. It is important to underline that, prior to performing water transport properties tests, we verified that no cracks were observed on the samples. In the following are exposed two major features of manufactured mortars, i.e. resistance to liquid water penetration and water vapour permeability.

Water vapour permeability of the cementitious material is also examined by means of the socalled "cup test" according to a CSTB procedure [14]. As a matter of fact, CSTB (Scientific and Technical Centre for Building, a state-owned industrial and commercial corporative placed under the administrative supervision of the French Ministry of Housing) helps the French public authorities to define technical regulations and ensure the quality of buildings. The hardened cement paste specimen was placed in the upper part of a metallic cup previously filled with $50 \mathrm{~g}$ of calcium chloride creating a very low relative humidity (about $0 \%$ at $23{ }^{\circ} \mathrm{C}$ ). The edges of the sample (interfaces with the cup) are sealed and the device is placed in a highly constant humid chamber $\left(90 \mathrm{RH} \%-23^{\circ} \mathrm{C}\right)$. In these conditions, the top surface of the specimen was exposed to $90 \mathrm{RH} \%$, with the bottom surface controlled near o RH \%. The water vapour in the chamber is thus forced to go to the dry ambiance, inside the cup, by passing through the sample. The device, shown in Figure 3, is regularly weighed until a constant mass gain is reached. Vapour permeability through the cement specimen was monitored by weighing the cup device until a steady rate of weight gain was achieved. In other words, the test was considered as completed when the rate of mass increase of the cup was 
linear, i.e. the material sample reached a steady-state in terms of moisture transport. The water vapour permeance $\Lambda$, in $\mathrm{kg} /\left(\mathrm{m}^{2} \mathrm{~s} \mathrm{~Pa}\right)$, is then defined by the (Equation 3 ).

$$
\Lambda=\frac{\mathrm{s}}{\mathrm{A} \times \Delta \mathrm{P}}
$$

Where $\mathrm{s}$ was the slope of the mass gain $(\mathrm{kg} / \mathrm{s})$ when the steady-state is reached, A was the surface area of the specimen $\left(\mathrm{m}^{2}\right)$ and $\Delta \mathrm{P}$ was the difference in water vapour pressure between the two ambiances at $23{ }^{\circ} \mathrm{C}(\Delta \mathrm{P}=2540 \mathrm{~Pa})$.

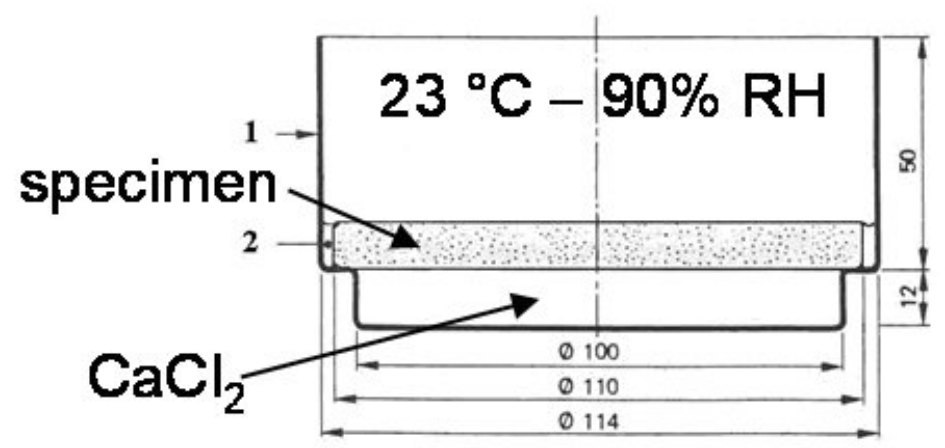

Figure 3: Test device to determine water vapour permeability. 1: metallic dish; 2: sealing. Dimensions are in $\mathrm{mm}$.

Liquid water penetration was determined using the apparatus shown in Figure 4. The test consists in maintaining a water level of $100 \mathrm{~mm}$ above the surface of the specimen and to measure the amount of water that passes through the specimen within $48 \mathrm{~h}$. Liquid water permeability, in $\mathrm{mL} / \mathrm{cm}^{2}$, is thus expressed as the amount of water going through the specimen per unit area of specimen surface. This method was formerly used in France to assess facade renderings [16] but was abandoned in the late 8os. However, it is still used to investigate laboratory-made materials because liquid water penetration appears as an interesting tool to investigate water transport on laboratory-made cement paste for fundamental studies.

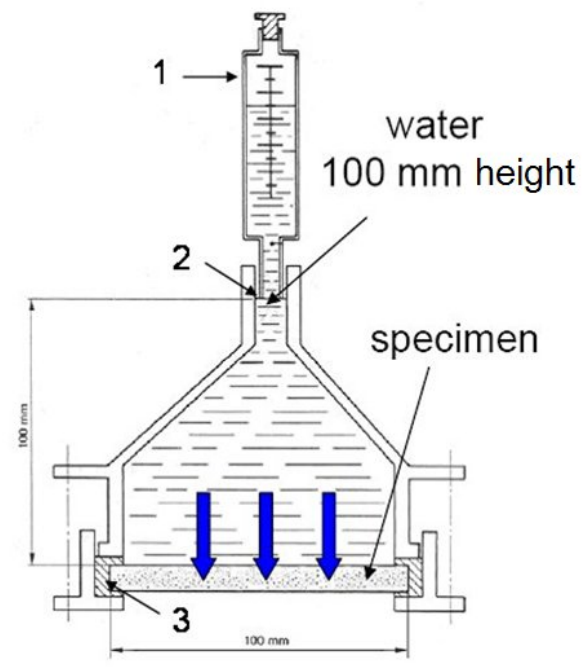

Figure 4: Test device to determine liquid water permeability.1: Set-up to keep constant water level and to measure flow; 2: constant level of water; 3: sealing. 


\section{III.5. Liquid water absorption by capillarity suction}

This test was defined in a CSTB standard [14] and [16] devoted to one-coat mortar, i.e. a designed rendering mortar applied in one coat which fulfils both functions of weatherproofing and decorative appearance of a "multi-coat" system.

Experiments were performed on hardened cement pastes (W/C $=0.4$ and $\mathrm{P} / \mathrm{C}=0.5 \mathrm{wt} . \%)$. Materials were prepared as usual $4 \times 4 \times 16 \mathrm{~cm}$ specimens, cured for about 28 days at $23{ }^{\circ} \mathrm{C}$ and $50 \mathrm{RH} \%$. This test was performed on controlled temperature and relative humidity chamber $\left(23{ }^{\circ} \mathrm{C}\right.$ and $\left.90 \mathrm{RH} \%\right)$. The principle of the test is to dip samples in vertical position in a $5 \mathrm{~mm}$ water bath. The liquid water absorption by capillary suction was then monitored by weighing specimens during $24 \mathrm{~h}$. The curve of absorption by capillary suction was obtained by plotting $\mathrm{M} / \mathrm{S}$ versus $\sqrt{ } \mathrm{t}$ (where $\mathrm{M}$ is the mass of the specimen in grams, $\mathrm{S}$ the section of the specimen in contact with the water bath in $\mathrm{cm}^{2}$, and the dipping time in minutes). The coefficient of absorption by capillary suction was defined as the slope of the straight line plotting between 10 and 90 min of dipping.

\section{Impact of cellulose ethers on entrained air}

\section{IV.1. Structuring of the porous media in fresh cement paste}

The main interest of fast X-ray microtomography is to elucidate the elaboration of the porous structure during the first hour of cement hydration. Our aim is to emphasize, in fresh state, the impact of $\mathrm{CE}$ chemistry on air voids using reiterated $3 \mathrm{D}$ volume investigations performed on the same sample region. To ensure comparability of results, the $3 \mathrm{D}$ images corresponding to different hydration stages of all admixed pastes were identically processed.

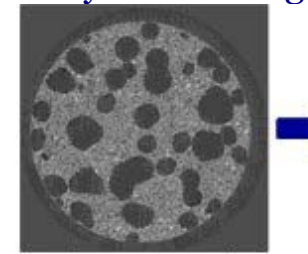

1. Reconstruefion

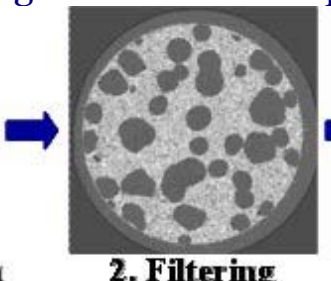

2. Filtering

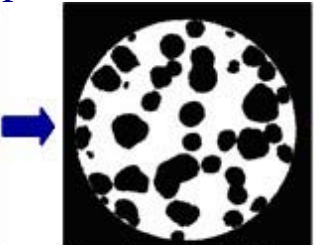

3. Thresholding

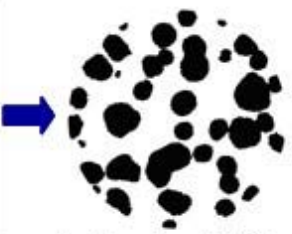

4. Border killing

Figure 5: Steps of image analysis to isolate and quantify pore sizes.

For quantification of pore sizes, different steps of image processing were performed on $3 \mathrm{D}$ images (Figure 5). Finally, pores were isolated within the images and then classified.

During the first hour of hydration, we noticeably observe for all pastes (admixed or not) a significant decrease of the volume fraction of small air voids as well as an increase of the volume fraction of big air bubbles. For example, Figure 6 shows that the global volume of air voids lower than $135 \mu \mathrm{m}$ decreases when the hydration time increases. Moreover, it appears that the global volume of air voids higher than $500 \mu \mathrm{m}$ increases with hydration time. Therefore, the evolution of the porosity of cement paste exhibits air voids coalescence.

More precisely, we distinguish two different mechanisms during this coalescence phenomenon. The first one corresponds to a very progressive increase of air voids size with a constant number of bubbles (Figure 7). The second mechanism leads to the decrease of the number of bubbles and the abrupt creation of bigger air voids by bubbles merging (Figure 8). Whether the second mechanism is obvious, the second one is not trivial. Indeed, different assumptions can explain the weak increase of bubbles observed during the first mechanism. Even if evaporation and chemical shrinkage may occur, all signs point to think that these factors are quite negligible. In this sense, we assume that the very progressive increase of air voids size may be induced by merging of a bubble (around 50-200 $\mu \mathrm{m}$ ) with numerous very small air voids (lower than $3 \mu \mathrm{m}$ ), which are not detected due to the spatial resolution of $2.8 \mu \mathrm{m}$ obtained with fast X-ray microtomography. 

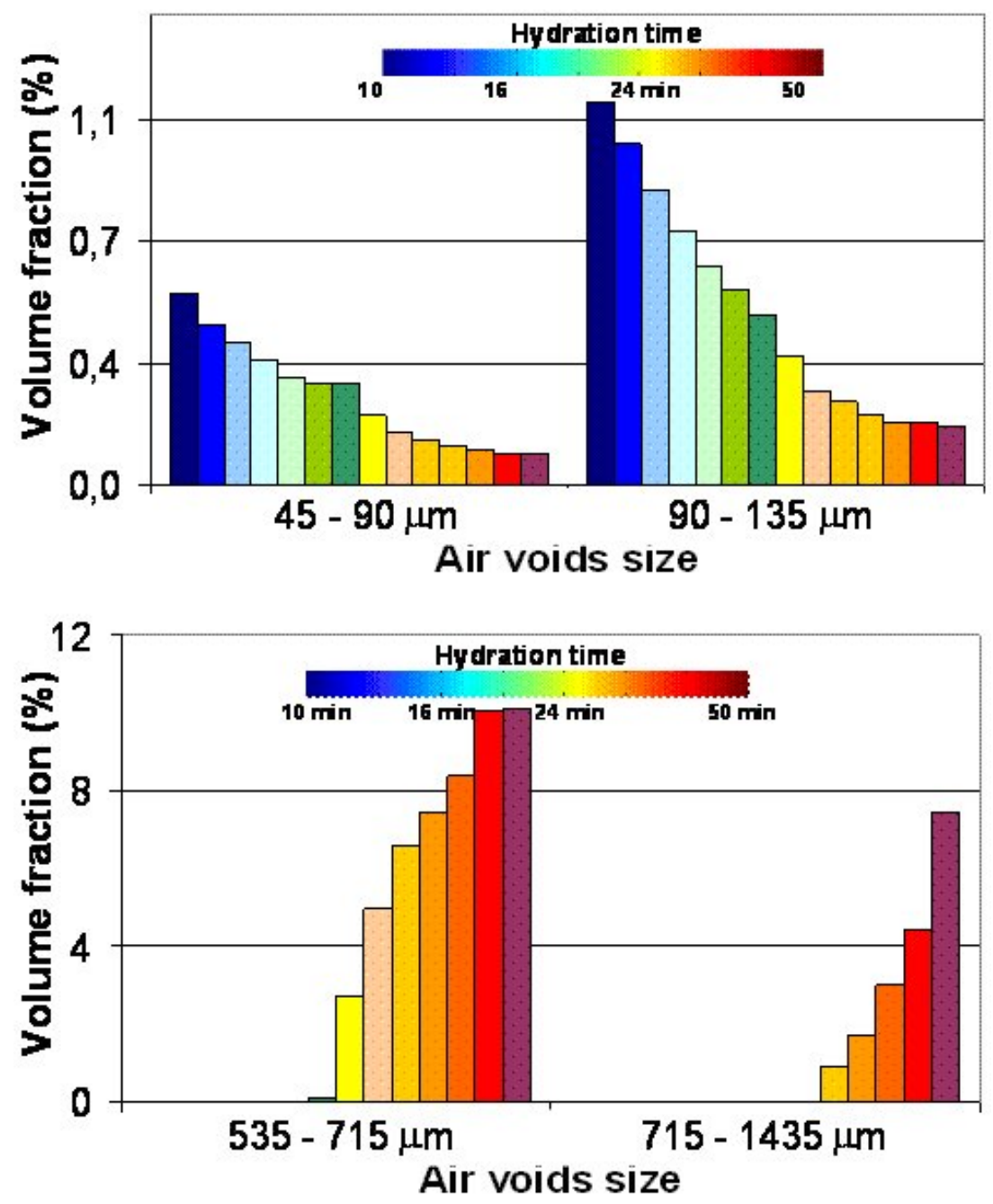

Figure 6: Example of the air voids size distribution as a function of the hydration time representative of all fresh cement pastes $(\mathrm{W} / \mathrm{C}=0.5-\mathrm{P} / \mathrm{C}=0.5 \%$ ) observed by fast X-ray microtomography.

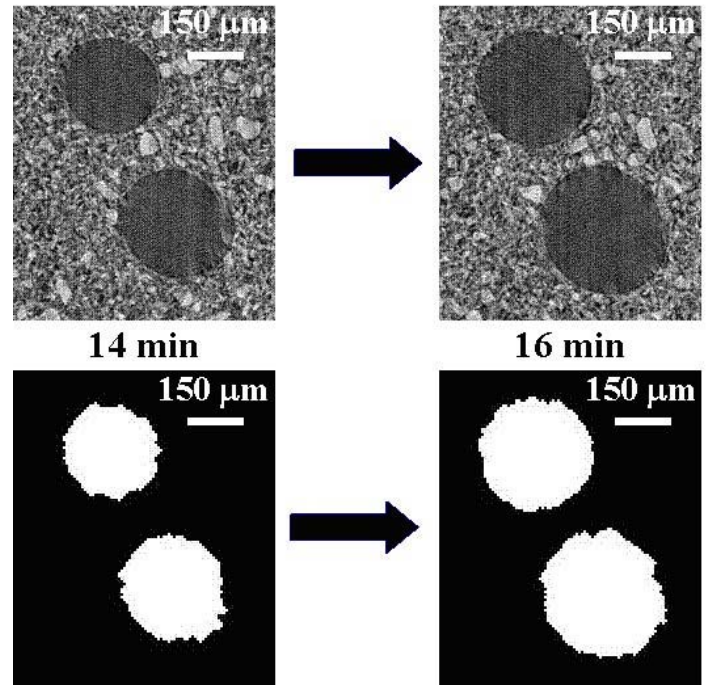

Figure 7: Images illustrating the first mechanism of air voids coalescence representative of all fresh cement pastes $(\mathrm{W} / \mathrm{C}=0.5-\mathrm{P} / \mathrm{C}=0.5 \%)$ observed by fast X-ray microtomography. 


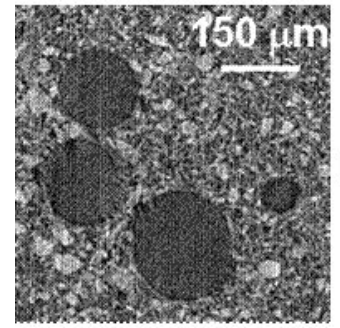

$14 \mathrm{~min}$

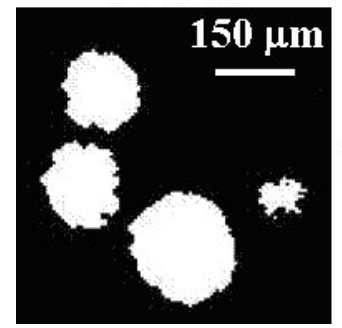

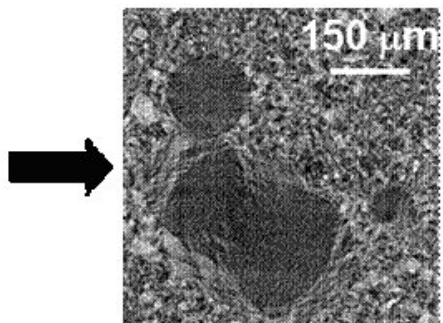

$16 \mathrm{~min}$

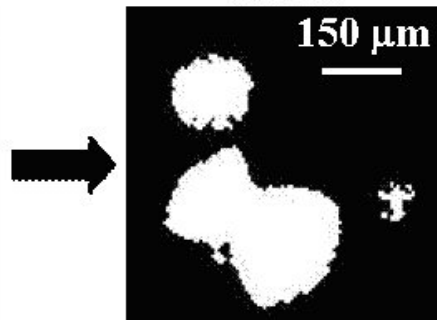

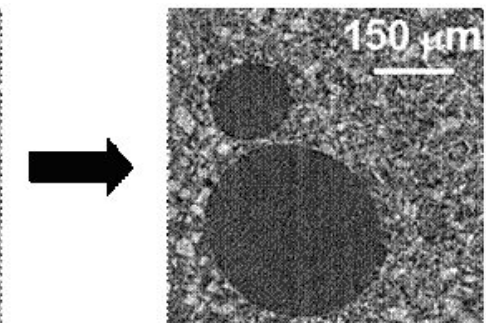

$18 \min$
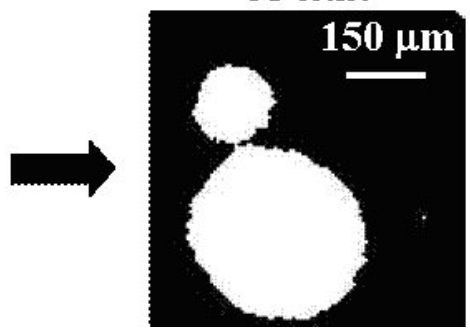

Figure 8: Images illustrating the second mechanism of air voids coalescence representative of all fresh cement pastes $(\mathrm{W} / \mathrm{C}=0.5-\mathrm{P} / \mathrm{C}=0.5 \%$ ) observed by fast X-ray microtomography.

As an example, when we follow changes of porosity in the same region of a H1-admixed cement paste, we observed these two different stages (Figure 9).

At the very beginning of cement hydration, we notice that air voids are too small and mobile to be precisely detected regarding to both temporal ( 1.5 min per scan) and spatial ( $2.8 \mu \mathrm{m}$ per pixel) resolution of fast X-ray microtomography. As a result, air bubbles appear as blurred in the first images until 15 min of hydration. Between 15 and 30 min of hydration, the first stage observed is mainly governed by the first mechanism of coalescence characterised by a weak increase of air voids size with an apparent constant number of air bubbles, certainly due to merging with numerous small air voids $(<3 \mu \mathrm{m})$ which are not detected. Then, during the second stage (30-50 min) the coalescence appears mainly piloted by the second coalescence mechanism, i.e. a decrease of air voids number due to big bubbles merging (i.e. 50-200 $\mu \mathrm{m}$ ). Furthermore, the quantification by image analysis of the volume fraction of air voids manifestly shows a progressive increase of the global porous volume until $30 \mathrm{vol} . \%$ at $50 \mathrm{~min}$ of hydration (Figure 10). We must underline that this porous volume fraction is clearly dependent on spatial and temporal resolution of microtomography experiments (e.g. small air voids lower than $3 \mu \mathrm{m}$ are "invisible"). Nevertheless, the two coalescence regimes detailed above are clearly distinguished for all samples.

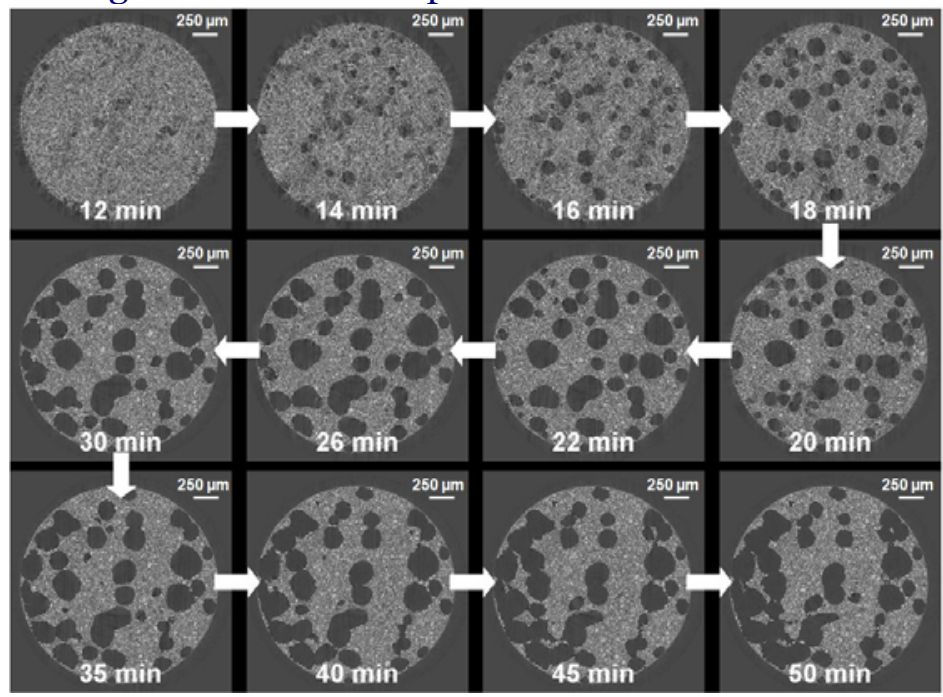

Figure 9: Evolution of the porosity observed by fast X-ray microtomography between 12 and 50 min of hydration in the same region of a H1-admixed cement paste $(\mathrm{W} / \mathrm{C}=0.5-\mathrm{P} / \mathrm{C}=0.5 \%)$. 
We notice also that the chemistry of CE have a significant influence on the porous media structuring in fresh state. Indeed, HPMCs obviously decrease the coalescence rate of both stage 1 and 2 compared to HECs. HPMCs allow also to stabilise big air voids (i.e. 50-200 $\mu \mathrm{m}$ ) after the mixing stage. In fact, the global volume of air content detected around $10 \mathrm{~min}$ of hydration for the HPMC P1-containing cement paste is significantly higher ( $>15$ vol.\%) by comparison of non-admixed and H1-containing cement pastes ( $<3$ vol.\%). Consequently, the porous network caused by HPMCs is more easily observed at the beginning of the hydration process since the air bubbles created during the mixing stage seems to be numerous, bigger and less mobile. In contrast, the addition of HECs seems to induce a slowing down of the coalescence rate of the stage 2, while no specific actions on the coalescence stage 1 and on the stabilisation of air voids during the mixing stage are observed.

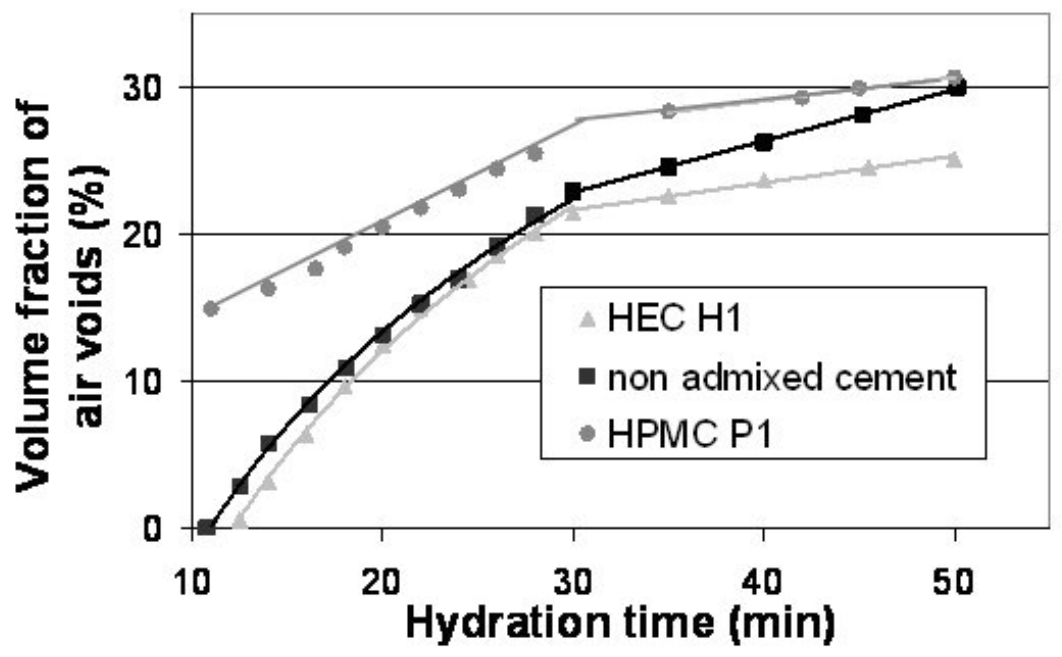

Figure 10: Impact of $\mathrm{CE}$ chemistry on the structuration of the porous media (cement paste, W/C $=0.5$ $-\mathrm{P} / \mathrm{C}=0.5 \%$ ) detected by fast X-ray microtomography.

This study confirms that air voids entrained during mechanical mixing can be stabilised by CE. Besides, the capacity of HPMCs to stabilise air voids seems to be more important by comparison with HECs. We assume that this difference may be correlated to different rheological behaviours, but also to dissimilar HECs and HPMCs affinity to the air-water interface. Fluorescence observation of stained CE as well as observation of mineral system by polarisation light microscopy, show clearly that HPMCs can more easily stabilise air bubbles thanks to polymer films formation at the air-wet cement interface (Figure 11). This specific ability of HPMCs can be assigned to surface-active agent properties, i.e. a strong affinity to the air-water interface. These results are perfectly in accordance with observations from ESEM experiments in freeze-dried samples of fresh mortars [3].

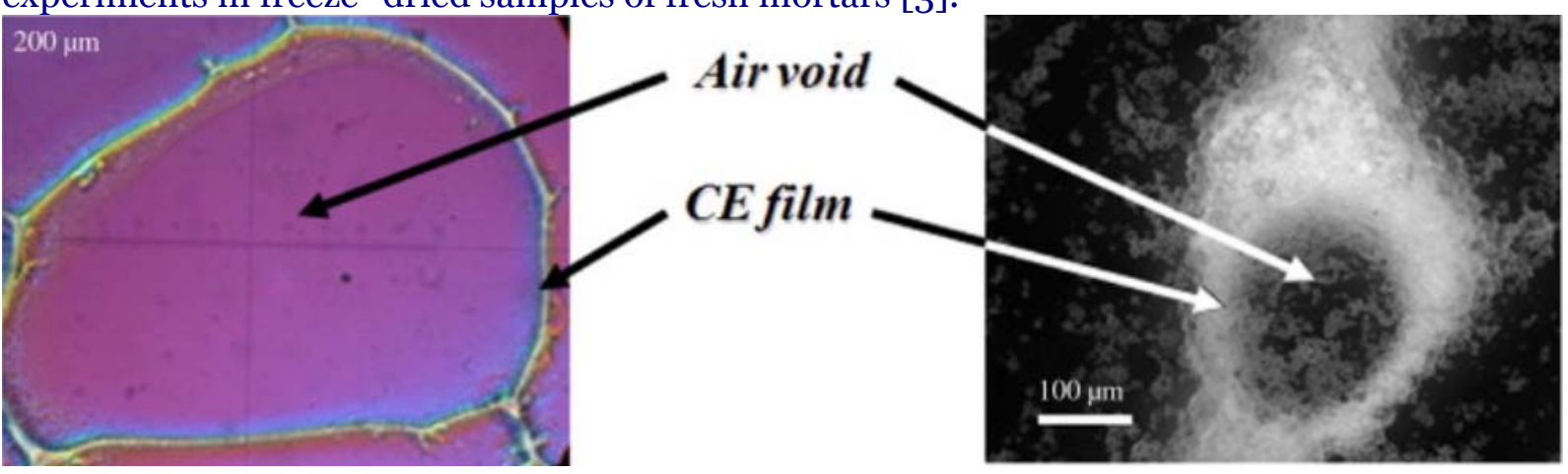

Figure 11: Examples of $\mathrm{CE}$ film at the air voids interface. Observation of $\mathrm{CE}$ solution by polarisation light microscopy (on the left). Investigation of the spatial distribution of FITC-CE stained on a filler$\mathrm{CE}$ - water system (on the right). 


\section{IV.2. Impact of $\mathrm{CE}$ on the porous structure in hardened cement paste}

The pore size cumulative distributions resulting from the MIP experiments are shown in Figure 12. A great influence of CE chemistry on the cement paste porosity is noticed. The total porous volume induced by HPMCs is significantly increased compared to the non-admixed sample. On the contrary, the porous volume of HECs cement paste and non-admixed cement paste is quite similar. The measurement of the apparent density of CE-modified cement paste corroborates that HPMCs leads to a higher porous volume rather than HECs (Table 2). Moreover, the apparent density of HPMC cement pastes (between 1.45 and 1.6) is perfectly in accordance with the order of magnitude of the air void content about 20 vol.\% determined by Jenni et al. [3]. The analysis of the differential intrusion curves gives also very interesting data on the small pores network (Figure 13). Two main peaks, corresponding to pore diameters range of $15-30 \mathrm{~nm}$ and 50-150 $\mathrm{nm}$, are observed for both HECs and HPMCs cement pastes. Besides, only for the HPMC-containing cement paste, a third peak appears in the diameter range $300-700 \mathrm{~nm}$. As a result, we demonstrate that the volume and distribution of large capillaries strongly depend on the CE chemistry, because HPMCs favour the apparition of 300-700 nm-diameter capillaries compared to HECs.

Table 2: Impact of $\mathrm{CE}$ on the apparent density of hardened cement paste $(\mathrm{W} / \mathrm{C}=0.4-\mathrm{P} / \mathrm{C}=0.5 \%-$ storage 14 days of $50 \mathrm{RH} \%$ and $23^{\circ} \mathrm{C}$ then $24 \mathrm{~h}$ vacuum-dried under $\mathrm{P} 2 \mathrm{O} 5$ ).

\begin{tabular}{lcccccc}
\hline Formulation & Cement & $\mathrm{N} 1$ & $\mathrm{~N} 7$ & $\mathrm{H} 1$ & $\mathrm{U} 2$ & $\mathrm{P} 1$ \\
\hline Apparent density $( \pm 0.01)$ & 1.92 & 1.91 & 1.85 & 1.83 & 1.62 & 1.45 \\
\hline
\end{tabular}

The 2D observations of cement paste macropores exhibit an important influence of CE on air void content. By image analysis, we highlight a higher capacity of HPMCs to stabilise an air void created during the mixing stage by comparison with HECs (Figure 14). This observation is in agreement with the results generated thanks to fast X-ray microtomography carried out in fresh cement paste (see paragraph IV.1). 3D microtomography observations of CEcontaining cement paste, in hardened state, emphasize a similar behaviour observed in 2D optical microscopy but with a higher spatial resolution ( $0.7 \mu \mathrm{m}$ per pixel). Examples of 2D images extracted from $3 \mathrm{D}$ volume are shown in Figure 15. The qualitative observation of the $3 \mathrm{D}$ volume indicates that HPMCs favour the formation of a high content of spherical air void, in the diameter range $50-250 \mu \mathrm{m}$.

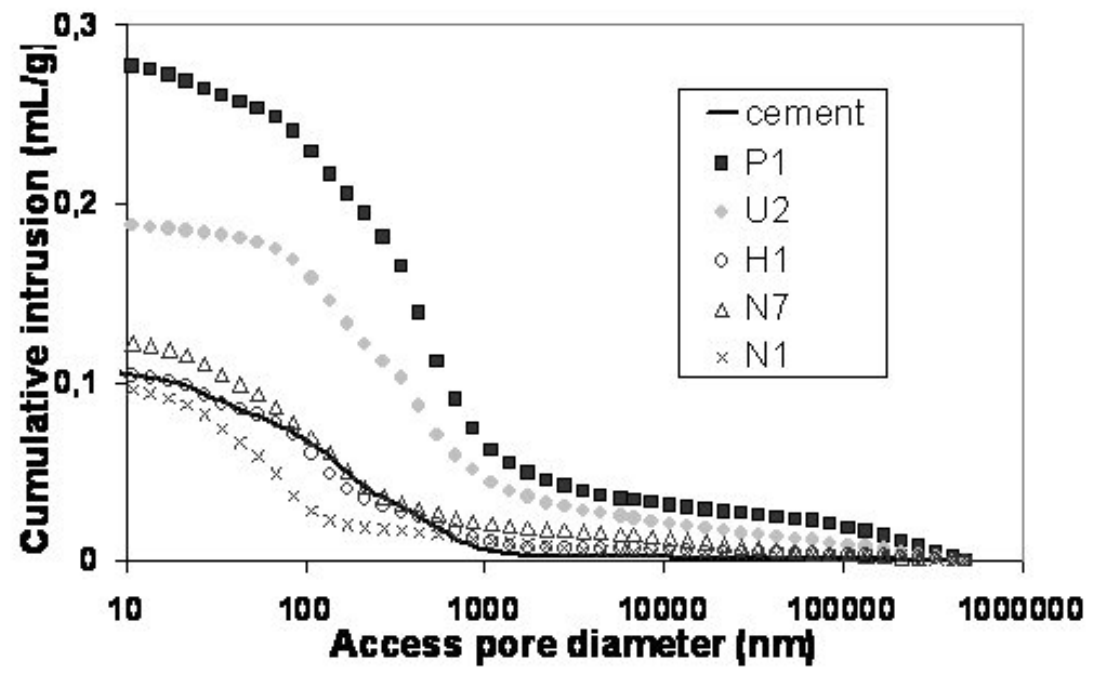

Figure 12: Impact of $\mathrm{CE}$ on the cumulative pore size distribution of hardened cement paste measured by mercury intrusion porosimetry $\left(\mathrm{W} / \mathrm{C}=0.4-\mathrm{P} / \mathrm{C}=0.5 \%\right.$ - storage 14 days of $50 \mathrm{RH} \%$ and $23^{\circ} \mathrm{C}$ then 24 h vacuum-dried under $\mathrm{P}_{2} \mathrm{O}_{5}$ ). 

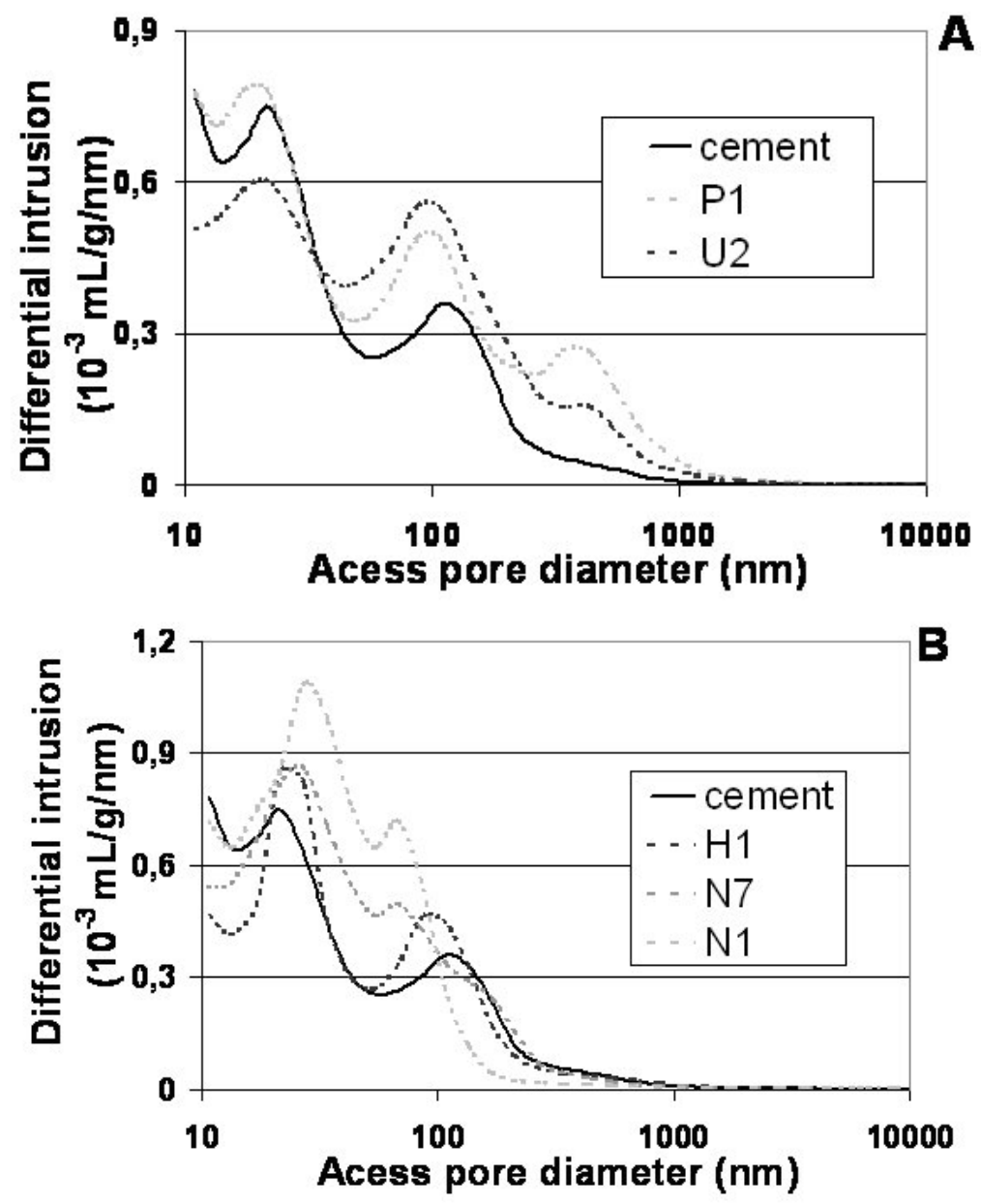

Figure 13: Impact of CE on the differential mercury intrusion of hardened cement paste $(\mathrm{W} / \mathrm{C}=0.4-$ $\mathrm{P} / \mathrm{C}=0.5 \%$ - storage 14 days of $50 \mathrm{RH} \%$ and $23^{\circ} \mathrm{C}$ then $24 \mathrm{~h}$ vacuum-dried under $\mathrm{P}_{2} \mathrm{O}_{5}$ ).

\section{Impact of cellulose ethers on water transport}

\section{V.1. Impact of $\mathrm{CE}$ on water retention in fresh laboratory mortar}

Water retention induced by $\mathrm{CE}$ was investigated using laboratory-made mortars admixed with CE. The results illustrated in Figure 16 show that the two normalized methods led to very similar values. Thus, the method applied appears to have no significant influence on the water retention capacity measured on fresh mortar. Obviously, a huge impact of CE chemistry on water retention is distinguished. We put in evidence an increase of water retention from $86 \%$ for low molecular mass HECs (H1 and N1), to 98\% for HPMCs and high molecular mass HECs (U2, $\mathrm{P}_{1}$ and N7) (Figure 17). The various effects of CE on water retention indicate that the CE molecular parameters (i.e. molecular mass and substitution groups) have a strong influence on such property.

V.2. Impact of $\mathrm{CE}$ on water transport in hardened cement paste

Experiments of liquid water absorption by capillary suction, water vapour permeability and liquid water penetration were performed on hardened cement pastes. We notice that CE lead to decrease the liquid permeability (Figure 18). Furthermore, a gradual effect bringing by different CE molecules on such properties is clearly observed. In fact, results highlight a great impact of CE chemistry on the liquid permeability capacity. Indeed HPMC molecules (P1 and U2) noticeably induce a lower liquid permeability of polymer-modified paste by comparison with HECs (H1, N1 and N7). We exhibit also that $\mathrm{CE}$ allows to increase the vapour permeability (Figure 19). Nevertheless, no specific influence of CE chemistry on vapour 
permeability of admixed pastes is obvious, even if we emphasize a permeance rise particularly enhanced for the HEC molecule called H1.

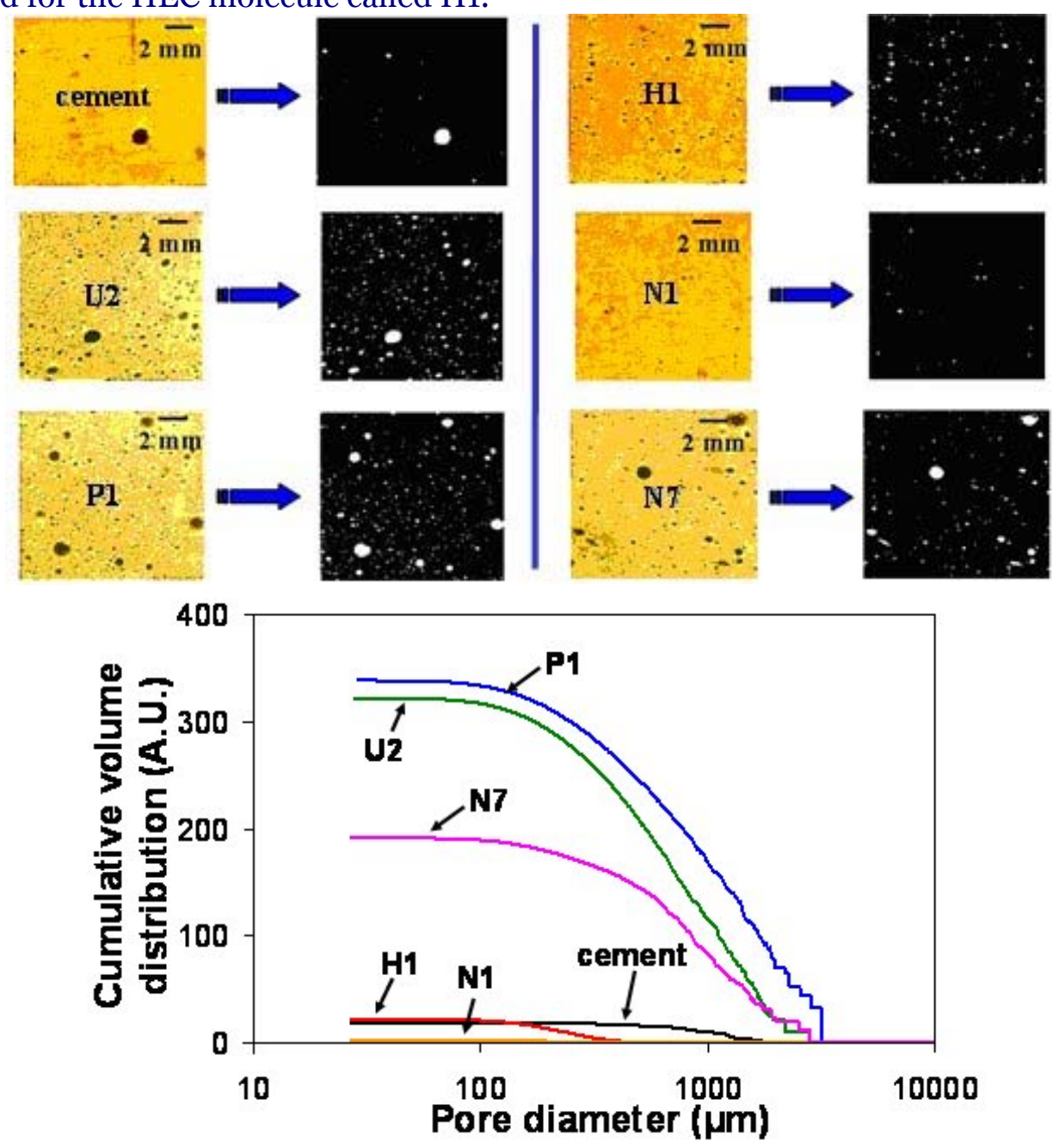

Figure 14: Representative examples of 2D image observation by optical microscopy of hardened cement paste $\left(\mathrm{W} / \mathrm{C}=0.4-\mathrm{P} / \mathrm{C}=0.5 \%\right.$ - storage 14 days of $50 \mathrm{RH} \%$ and $23^{\circ} \mathrm{C}$ then $24 \mathrm{~h}$ vacuumdried under $\mathrm{P}_{2} \mathrm{O}_{5}$ ), and impact of $\mathrm{CE}$ on air voids cumulative distribution calculated by image analysis.

Finally, the results on water absorption by capillarity exhibit three main behaviours depending of $\mathrm{CE}$ chemistry (Figure 20). In presence of HECs $\mathrm{N}_{7}$ and $\mathrm{N} 1$, having different molecular weights and a same substitution degree of $56 \% \mathrm{EOOH}$, a water absorption coefficient similar to that of the non-admixed cement paste is noticed (around $4.5 \mathrm{~g} \mathrm{dm}^{-2} \min ^{-0.5}$ ). By contrast, HEC $\mathrm{H} 1$ and HPMC U2 induce a lower water absorption coefficient, i.e. $3 \mathrm{~g} \mathrm{dm}^{-2} \mathrm{~min}^{-0.5}$. Then, a remarkable behaviour is observed for the HPMC P1 with a very low water absorption coefficient, i.e. $1 \mathrm{~g} \mathrm{dm}^{-2} \mathrm{~min}^{-0.5}$.

\section{Discussion and conclusion}

The fluid movement within unsaturated cement-based materials is a hard issue owing to the complex and multi-scale porous structure. Thus, the knowledge of the CE impact on both porous structure and water transport characteristics are basic data allowing to improve our understanding of CE-modified cement-based material. In this context, this paper aims at linking microstructure and water transport with respect to CE chemistry. 

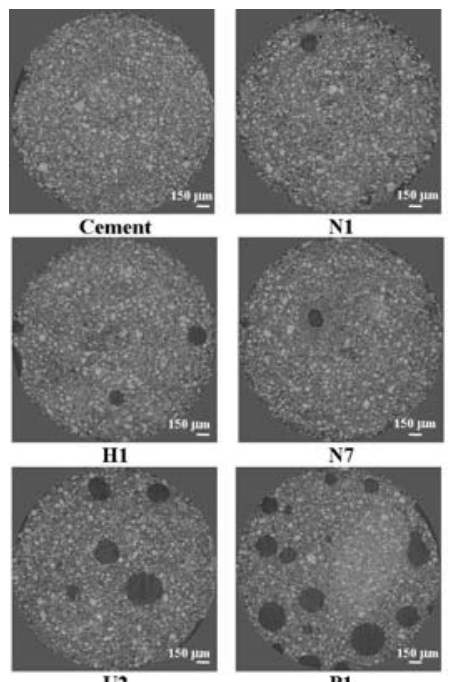

Figure 15: Representative examples of 3D image observation by X-ray microtomography of hardened cement paste $\left(\mathrm{W} / \mathrm{C}=0.4-\mathrm{P} / \mathrm{C}=0.5 \%\right.$ - storage 14 days of $50 \mathrm{RH} \%$ and $23^{\circ} \mathrm{C}$ then $24 \mathrm{~h}$ vacuumdried under $\mathrm{P}_{2} \mathrm{O}_{5}$ ).
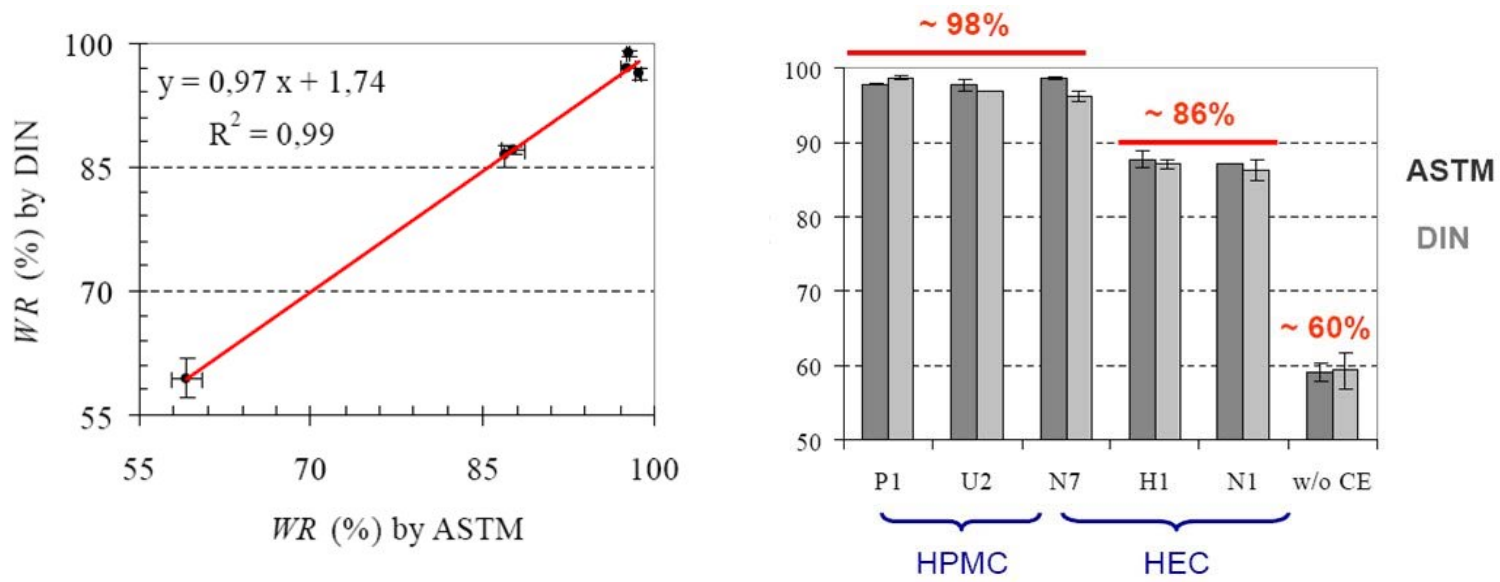

Figure 16: Water retention of a fresh mortar Figure 17: Water retention of a fresh mortar admixed with different types of CE: correlation admixed with different types of CE: impact of between ASTM and by DIN methods. $\mathrm{CE}$ chemistry on water retention values (the reference mortar without cellulose ether addition is noted $\mathrm{w} / \mathrm{o} \mathrm{CE}$ ).

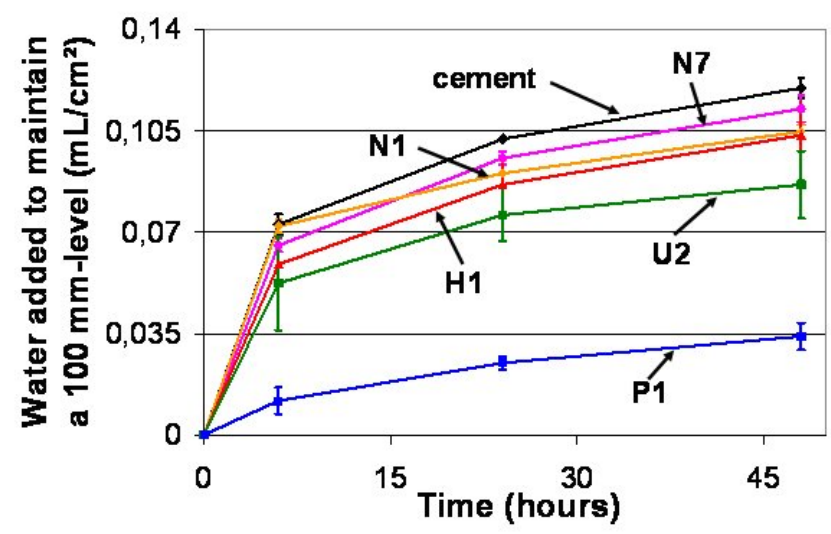

Figure 18: Impact of $\mathrm{CE}$ on the liquid water permeability on hardened cement paste $(\mathrm{W} / \mathrm{C}=0.4-$ $\mathrm{P} / \mathrm{C}=0.5 \%$ - storage 14 days of $50 \mathrm{RH} \%$ and $23^{\circ} \mathrm{C}$ ). 


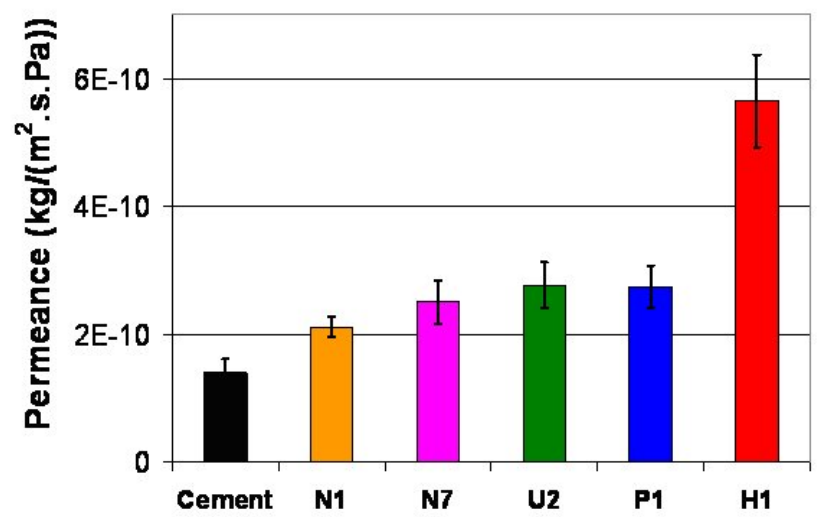

Figure 19: Impact of $\mathrm{CE}$ on the vapour permeability on hardened cement paste (W/C $=0.4-$ $\mathrm{P} / \mathrm{C}=0.5 \%$ - storage 14 days of $50 \mathrm{RH} \%$ and $23^{\circ} \mathrm{C}$ ).

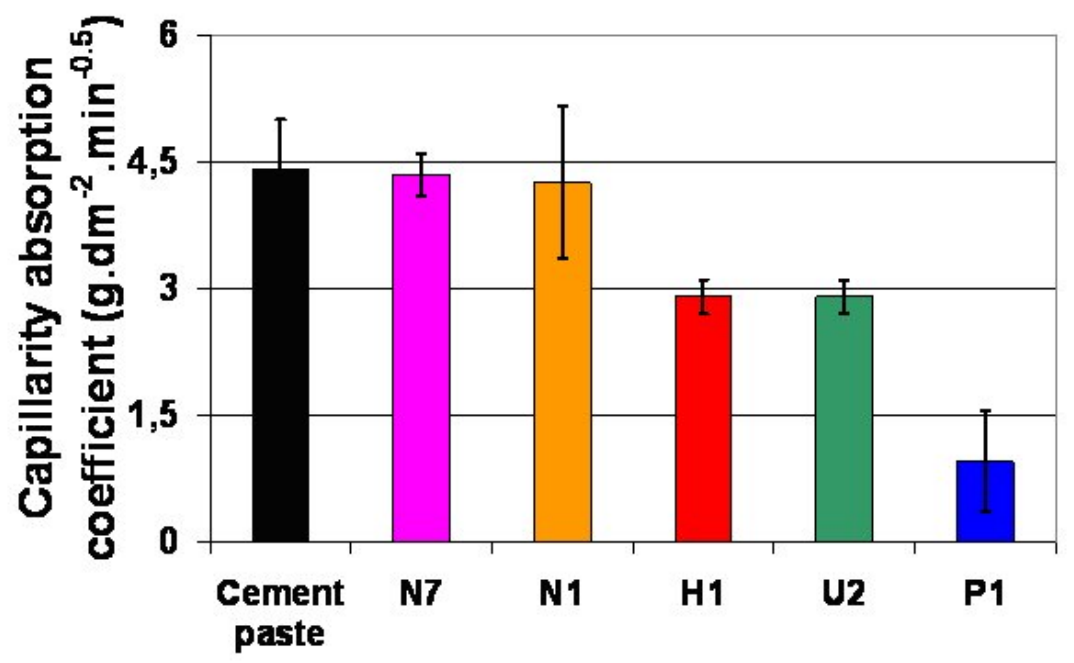

Figure 20: Effect of $\mathrm{CE}$ on the water absorption by capillarity on hardened cement paste (W/C $=0.4$ $-\mathrm{P} / \mathrm{C}=0.5 \%$ - storage 14 days of $50 \mathrm{RH} \%$ and $23 \mathrm{C}$ ).

First of all, complementary investigation tools (MIP, 2D and 3D observations coupled with image analyses) were developed in order to examine the effects of $\mathrm{CE}$ on cement paste microstructure. The obtained results show that CE may generate an increase of both 50$250 \mu \mathrm{m}$-diameter air voids and capillary pores around $500 \mathrm{~nm}$-diameter. The CE chemistry appears as a key parameter on the porous structure development.

Besides, we demonstrate that $\mathrm{CE}$ addition brings to the hardened cement pastes a lower capillarity water absorption, a lower liquid water permeability and a higher water vapour permeability compared to non-admixed cement paste. Of course, we must bear in mind that the extrapolation to mortar of results generated in cement pastes is not trivial. Moreover, a higher water retention is also obviously put in evidence in fresh CE-admixed mortar by comparison with non-admixed mortar. To sum up, gradual effects on hydric transfers are always clearly observed as a function of CE chemistry. Thus, one of the main conclusions of this preliminary study is that CE chemistry (HECs or HPMCs, i.e. nature of the substitution groups) and the structure parameters (molecular mass and content of substitution groups) seem to be important controlling factors on water transport and porous structure in both fresh and hardened state of cementitious materials.

To explain such behaviour, one of strongest hypotheses is the formation of a porous network caused by CE, which may have a specific action on hydric transfers mechanism as a function of the number of air voids (in the diameter range 50-250 $\mu \mathrm{m}$ ) and capillary pores (in the diameter range $100-700 \mathrm{~nm}$ ). A decrease of the pore size may induce a slowing down of 
transfer in liquid phase because of viscous fluid law. Moreover, pores size lower than $1 \mu \mathrm{m}$ are very sensitive to capillary condensation and can be filled by liquid water. So, the porous structure can be partially filled with liquid water, and large unsaturated porous spaces can isolate some liquid water pouch. In a first approach, three cases of hydric transfer could be distinguished: vapour diffusion, vapour diffusion assisted by liquid flow, and finally liquid capillary flow in the case of saturated cement-based materials. As a function of the microstructure characteristics caused by $\mathrm{CE}$ (number, size and $3 \mathrm{D}$ spatial arrangement of pores), a regime of water transfer in both liquid and gas phases can appear. As an example, the porous structure described in Figure 21 corresponds to the microstructure characteristics generated by HPMCs (P1 and U2). This porous organization can typically cause a water transport kinetic regime characterised by vapour diffusion in large air voids assisted by capillary flow in the $100-700 \mathrm{~nm}$ capillaries. This specific kinetic regime may explain the lower liquid water permeability measured in presence of HPMCs. Indeed, when the cement paste does not contain any $\mathrm{CE}$, this leads to a liquid permeability occurring by means of a "fast" capillary flow kinetic regime. Besides, the porous structure caused by CE impose a part of water transport by means of "slow" vapour diffusion due to the presence of a great number of 50-250 $\mu \mathrm{m}$-diameter air voids which play the role of "short circuit". In this sense, the chemistry of $\mathrm{CE}$ due to characteristics of the porous media generated, may (at least partially) explain the lower liquid water permeability measured in addition of CE.
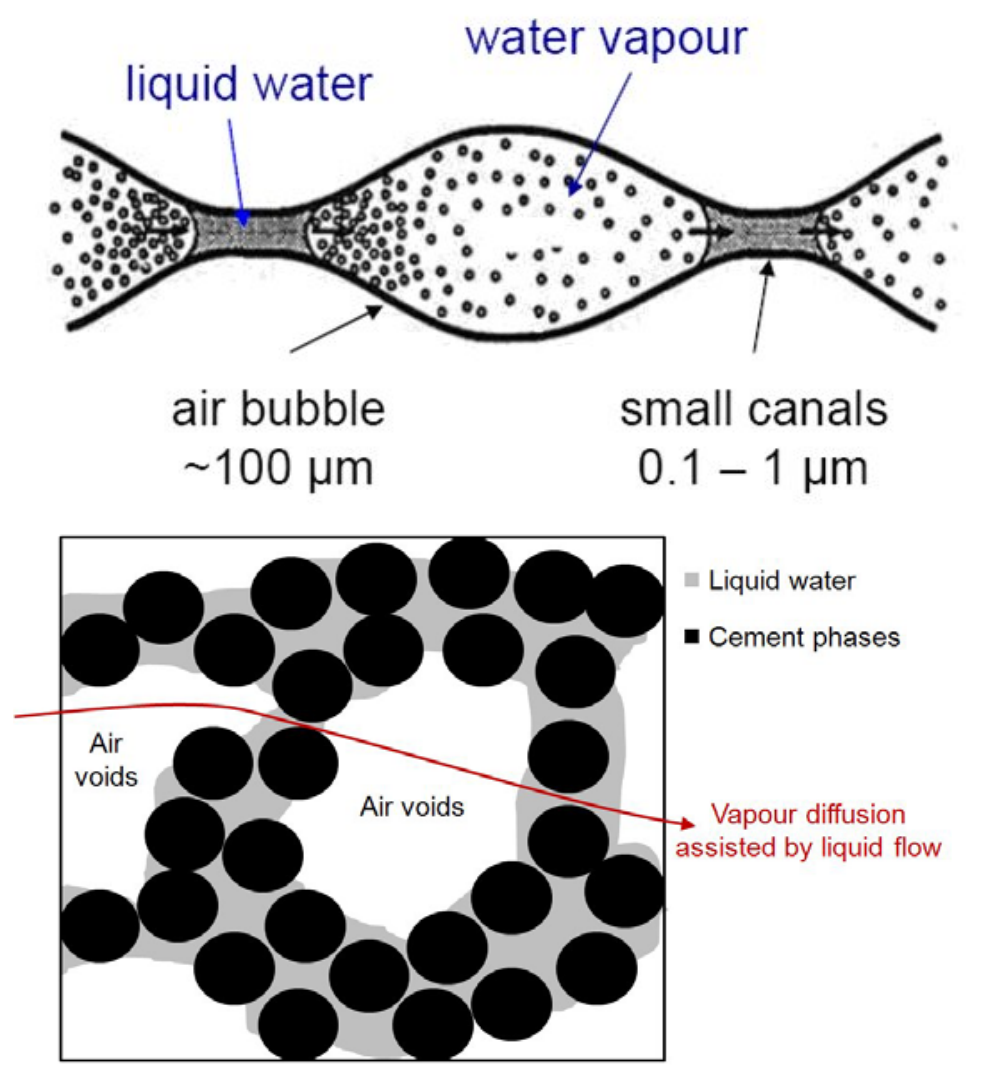

Figure 21: Model porous network characterised for the HPMCs P1 and U2, and description of hydric transfer transport through this specific microstructure.

\section{Acknowledgements}

The authors would like to acknowledge the financial support of FedeRAMS (Fédération CNRS 2145 " Matériaux de Structure et Propriétés d'Usage») and international CEReM network (consortium for study and research on mortars - http://cerem.cstb.fr). We also extend our thanks to Elodie Boller (ESRF - ID19 beamline) and Eric Maire (UMR 5510 - FedeRAMS) for their help and fruitful discussions on microtomography experiments. 


\section{References}

[1] M. Malatrait, Propriétés hydriques du mortier pour enduits de façades en relation avec sa structure poreuse, mise en oeuvre, durabilité, $\mathrm{PhD}$ thesis, INP Toulouse University (1992).

[2] D.A. Silva, V.M. John, J.L.D. Ribeiro and H.R. Roman, Pore size distribution of hydrated cement pastes modified with polymers, Cement and Concrete Research 31 (2001), pp. $1177-1184$.

[3] A. Jenni, L. Holzer, R. Zurbriggen and M. Herweg, Influence of polymers on microstructures and adhesive strengh of cementitious tile adhesive mortars, Cement and Concrete Research 35 (2005), pp. 35-50.

[4] A. Jenni, R. Zurbriggen, L. Holzer and M. Herweg, Changes in microstructures and physical properties of polymer-modified mortars during wet storage, Cement and Concrete Research 36 (2006), pp. 79-90.

[5] E. Knapen and D. van Gemert, Cement hydration and microstructure formation in the presence of water-soluble polymers, Cement and Concrete Research 39 (2009), pp. 613.

[6] S. Hucko, Hot climate render additive, in: Proceedings of the V Simpósio Brasileiro de Tecnologia das Argamassas Brazilian Symposium of Mortars Technology, São Paul (Brazil) (2003), pp. 3-11.

[7] H. Paiva, L.P. Esteves, P.B. Cachim and V.M. Ferreira, Rheology and hardened properties of single-coat render mortars with different types of water retaining agents, Construction and Building Materials 23 (2009), pp. 1141-1146.

[8] M.U.K. Afridi, Y. Ohama, M. Zafar Iqbal and K. Demura, Water retention and adhesion of powdered and aqueous polymer-modified mortars, Cement and Concrete Composites 17 (1995), pp. 113-118.

[9] J.M. Aldred, S. Swaddiwudhipong, S.L. Lee and T.H. Wee, The effect of initial moisture content on water transport in concrete containing a hydrophobic admixture, Magazine of Concrete Research 53 (2001), pp. 127-134.

[10] M.J. Mosquera, B. Silva, B. Prieto and E. Ruiz-Herrera, Addition of cement to lime-based mortars: effect on pore structure and vapor transport, Cement and Concrete Research 36 (2006), pp. 1635-1642.

[11] Y. Sebaibi, R.M. Dheilly and M. Queneudec, Study of the water-retention capacity of a lime-sand mortar: influence of the physicochemical characteristics of the lime, Cement and Concrete Research 33 (2003), pp. 689-696.

[12] J. Pourchez, P. Grosseau, R. Guyonnet and B. Ruot, HEC influence on cement hydration measured by conductometry, Cement and Concrete Research 36 (2006), pp. 1777-1780.

[13] American Society for Testing and Materials, Standard C91 section 7.2 and 7.3, Specification for masonry cement: determination of water retention and air content (2003).

[14] Certification CSTB des enduits monocouches d'imperméabilisation, Modalités d'essais, cahier du CSTB n 3207, livraison 407 (2000).

[15] Deutches Institut fur Normung, DIN 18555-7, Testing of mortars containing mineral binders, part 7: Determination of water retentivity of fresh mixed mortar by the filter plate method (2000).

[16] CSTB, Modalités d'essais des enduits extérieurs d'imperméabilisation de mur à base de liants hydrauliques, cahier du CSTB n 1779 (1982). 